\title{
Discharge of Spacecraft Solar Panels by Hypervelocity Impact
}

\author{
By Shirou KAWAKITA ${ }^{1)}$, Go SEGAMI ${ }^{1)}$, Kumi NITTA ${ }^{1)}$, Hiroaki KUSAWAKE ${ }^{1)}$, \\ Masato TAKAHASHI ${ }^{1}$, Haruhisa MATSUMOTO ${ }^{1)}$ and Sunao HASEGAWA ${ }^{2)}$ \\ 1) Aerospace Research and Development Directorate, JAXA, Tsukuba, Japan \\ ${ }^{2)}$ Institute of Space and Aeronautical Science, JAXA, Kanagawa, Japan
}

(Received April 30th, 2008)

\begin{abstract}
Small particles of less than $0.5 \mathrm{~mm}$ diameter collide with spacecraft solar panels, which work as an electrical power supply. Sustained arc discharging does not occur during such impacts, although trigger discharges are generated during several hundreds of milliseconds. The electrical performance of the solar panels is degraded slightly, but not enough to affect satellite systems.
\end{abstract}

Key Words: Solar Panel, Hypervelocity Impact, Orbital Debris, Degradation

\section{Introduction}

The Advanced Earth-Observing Satellite II (ADEOS-II) displayed anomalous operation on October 25, $2003{ }^{1)}$. The satellite's generated power suddenly decreased from $6 \mathrm{~kW}$ to $1 \mathrm{~kW}$. Damage to the electrical power cables caused by electrostatic discharge (ESD) was one cause. Before this anomaly, the electrical power of the seven solar arrays had degraded over seven months. One reason for this degradation was the impact of small particles (orbital debris and meteoroids). Furthermore, Russian satellites (VEGA-1 and 2), which observed a comet and Venus, showed electrical power degradation in 1984 resulting from impacts of small particles on the solar panel. Impact tests were carried out for a small solar panel to evaluate this reason ${ }^{2)}$. The particle's size and velocity were 0.1 to $10 \mu \mathrm{m}$ and $10-15 \mathrm{~km} / \mathrm{s}$, respectively. The panel power was decreased due to the fluence of $10^{5}-10^{6}$ particles resulting from the decrease of the shunt resistance of solar cells.

To provide increased solar generation power, the solar panel of the Hubble space telescope satellite was changed to a new one 1320 days after launch. An overview inspection on the solar panels was conducted, more than 2000 small damage points from impact were found. The average large damage-point count, where the diameter was more than $0.1 \mathrm{~mm}$, was eight particles per square meter ${ }^{3)}$, but no degradation in power generation was found.

Four modes of solar panel degradation by impacts of small particles in space are described below.

(1) Short circuits by contact between a solar cell and the substrate.

(2) Short circuits between a solar cell and the substrate by discharge due to impact.

(3) Short circuits due to discharge in a LEO plasma environment triggered by impact.

(4) Short circuits by discharge arising from damage by impacts in a space environment.

This paper describes impact tests conducted to evaluate (1) and (2) using a solar panel.

\section{Experiments}

\subsection{Solar Panel}

An overview of a solar panel is depicted in Fig. 1. The solar panel has 15 space silicon solar cells on a substrate. The cells and panels are $40 \mathrm{~mm} \times 60 \mathrm{~mm}$ and $300 \mathrm{~mm} \times$ $300 \mathrm{~mm}$ respectively.

Figure 2 portrays the solar panel structure. A $100-\mu \mathrm{m}$ thick-coverglass was attached to each solar cell. The substrate structure was a honeycomb structure made of aluminum with a carbon fiber reinforced plastics (CFRP) skin. The substrate thickness was $25.4 \mathrm{~mm}$.

The panel has 15 solar cells, arrayed as three parallels of five series. The solar cells were supplied with voltage and current from an electrical power supply. The voltages were $60 \mathrm{~V}$ and $110 \mathrm{~V}$; the respective currents were 2 and 3 A. These conditions are those of typical electrical power of satellites. The panel substrate was connected to the return line of the power supply.

The signals of the voltage and current of the supply were measured in order to evaluate the discharge induced by impacts. The configuration of measurement points is shown in Fig. 3. 


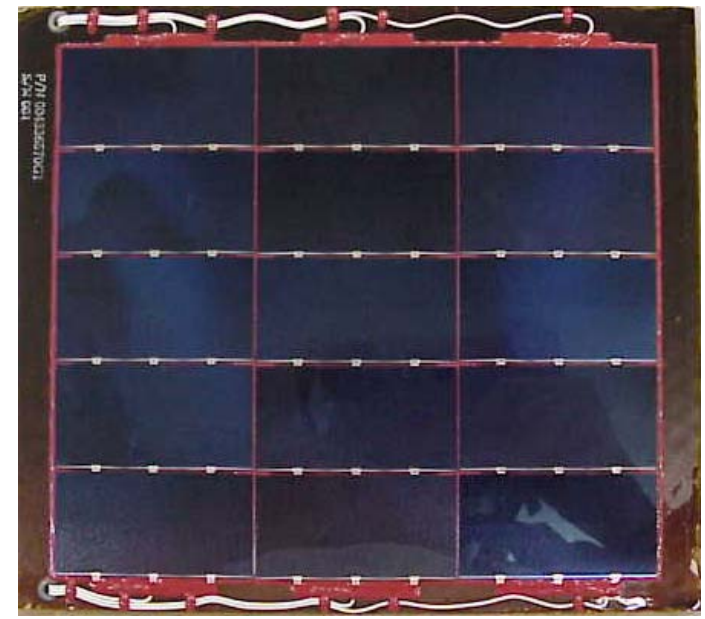

Fig. 1. Space silicon solar cell panel.

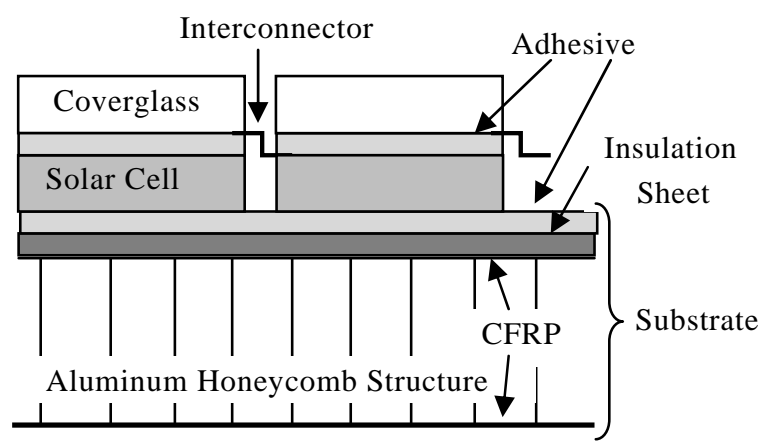

Fig.2. Structure of the solar panel. The thickness of coverglass and solar cell is $0.1 \mathrm{~mm}$. The thickness of substrate is $25.4 \mathrm{~mm}$.

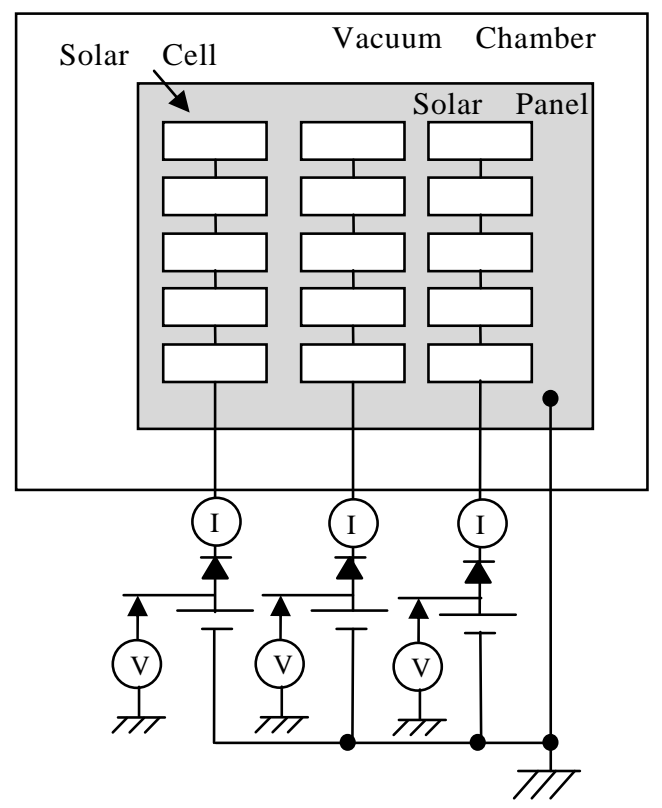

Fig.3. Electrical circuit for impact tests.

\subsection{Impact Test}

A two stage light gas gun was used for impact tests at ISAS in JAXA. A photograph of the gun is shown in Fig. 4. The solar panel was placed in a vacuum chamber at the end of the gun. The panel in the chamber is presented in Fig. 5. The vacuum pressure was around $10 \mathrm{~Pa}$. Small particles were irradiated perpendicularly to the panel surface.

The materials of small particles used were glass and alumina as a dielectric, and aluminum and stainless steel as a conductor. These materials are typical of those in space as reported.

The particle diameters were 0.1-0.5 mm, because these particles caused damage significantly on satellites and the probability of impact with the satellite was significant. The particle velocity was the range from 3 to $4 \mathrm{~km} / \mathrm{s}$.

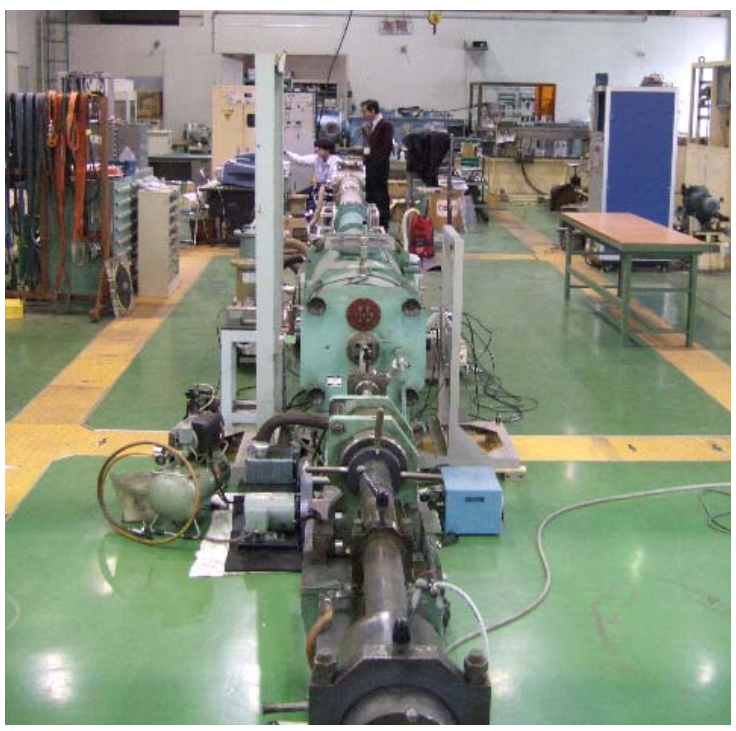

Fig.4. Two-stage light gas gun.

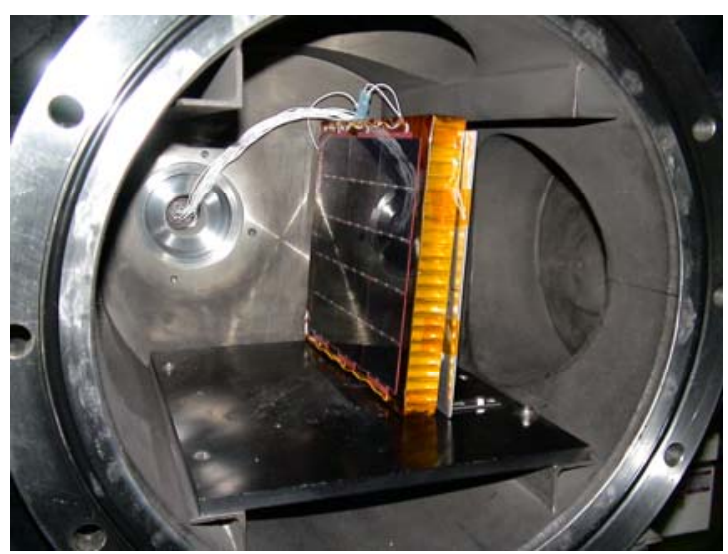

Fig.5. Solar panel placed in the vacuum chamber. Particles come from the left side of this photograph. 


\section{Results and Discussion}

\subsection{Dielectric Particles}

Small glass particles $0.1 \mathrm{~mm}$ in diameter were impacted onto the solar panel. Their velocity was $3.4 \mathrm{~km} / \mathrm{s}$.

Discharge provided by means of the power supply occurred at impact. Such a discharge, lasting $2 \mathrm{~ms}$, is shown in Fig. 6.

Much damage, as illustrated in Fig. 7, occurred in a small area. One solar cell had more than 50 damage cases. The depth of damage was less than $0.1 \mathrm{~mm}$, which indicates that the particles did not penetrate the coverglass.

Glass particles $0.15 \mathrm{~mm}$ diameter hit the panel causing about 20 damages. A view of the damage using a microscope is presented in Fig. 8. Damage as like a wave was found at the center of the impact. This figure was formed by rapidly increasing the temperature at the

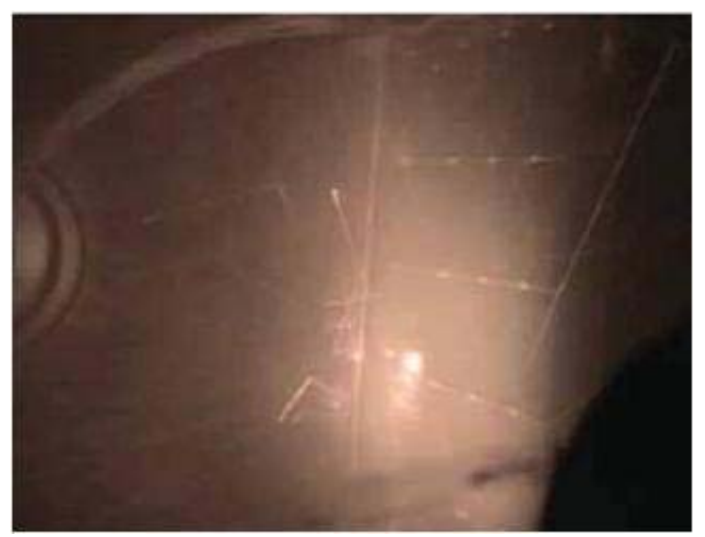

Fig.6. Discharge at impact.

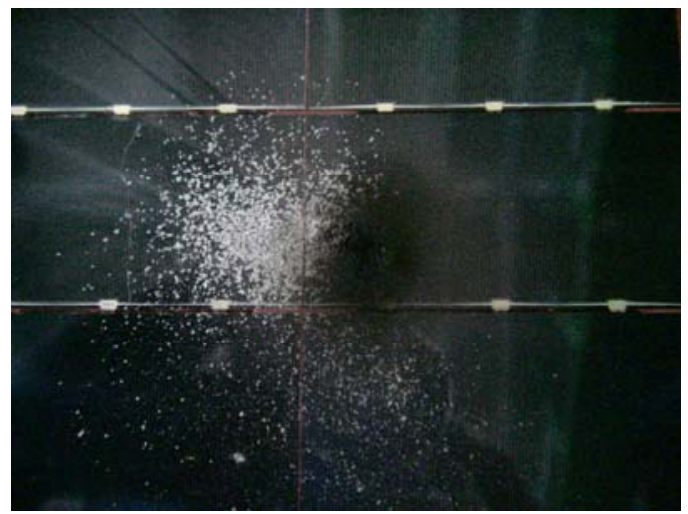

Fig.7. Impact damage produced with $0.1 \mathrm{~mm}$ glass particles. Their velocity was $3.4 \mathrm{~km} / \mathrm{s}$.

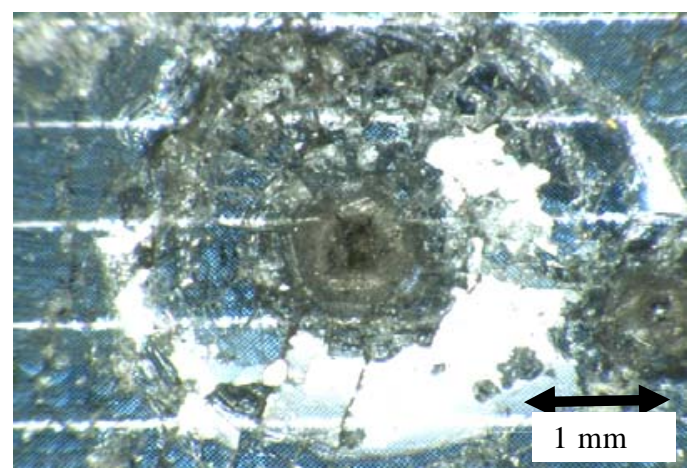

Fig.8. Impact damage produced by a $0.15 \mathrm{~mm}$ glass particle. The velocity was $3.4 \mathrm{~km} / \mathrm{s}$.

impact, then decreasing after the impact. No discharge was generated during the test.

Alumina particles $0.5 \mathrm{~mm}$ diameter collided with the panel. One panel showed two instances of damage case by the impact test. The particles passed through the panel. No discharge occurred during this test. One damage case is depicted in Fig. 9.

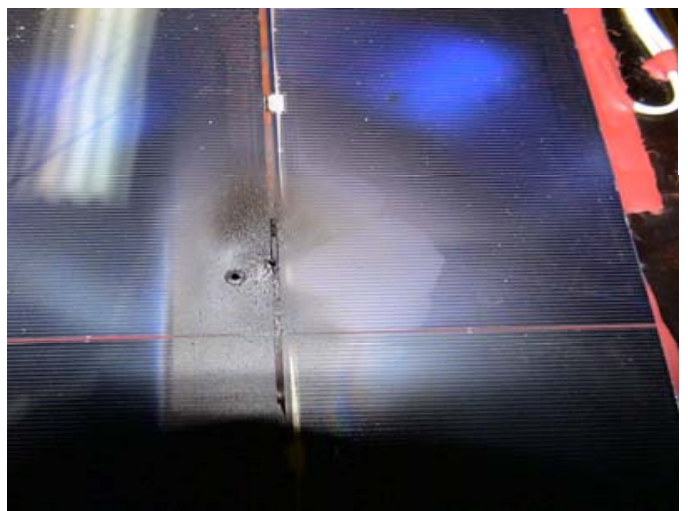

Fig.9. Damage generated by a $0.5 \mathrm{~mm}$ particle.

The electrical performance of the solar cells was measured before and after the impact tests. Penetration of the solar panel was up to the coverglass in the $0.1 \mathrm{~mm}$ particle test, the solar cells in the $0.15 \mathrm{~mm}$ test, and completely in the $0.5 \mathrm{~mm}$ tests. The cells that had collided with $0.1 \mathrm{~mm}$ diameter particles were degraded slightly. The performance before and after the test is presented in Fig. 10. Cell damage by $0.15 \mathrm{~mm}$ and $0.5 \mathrm{~mm}$ diameter particles showed almost identical performance before and after the tests. Two types of degradation caused it. One is decreased transmittance of the coverglass; the other is degradation of the fill factor induced by decreasing the cell shunt resistance. Furthermore, the higher degradation of cells irradiated with $0.1 \mathrm{~mm}$ diameter particles was comparable to that induced by $0.15 \mathrm{~mm}$ and $0.5 \mathrm{~mm}$ particles on cells with the $0.1 \mathrm{~mm}$ particle test. 


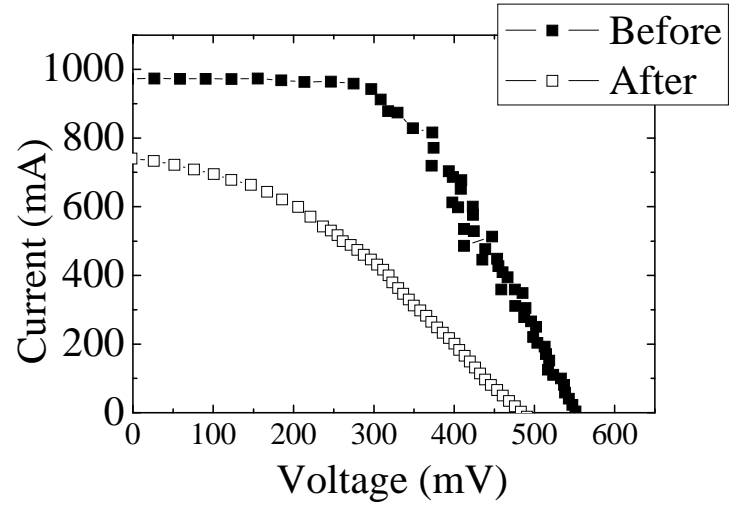

Fig.10. Change in the electrical performance of the most damaged solar cell on the panel before and after the impact test.

\subsection{Conductive Particles}

Aluminum flakes of $0.15 \mathrm{~mm}$ in diameter were impacted on the solar panel so as to evaluate the degradation dependence on the particle conductivity. The power supply had a voltage of $100 \mathrm{~V}$ and a current of $2 \mathrm{~A}$. The damage was of the same size in the cells as that produced by $0.15 \mathrm{~mm}$ aluminum particles. Discharging for approximately $200 \mathrm{~ms}$ was observed during this test. The electrical performance of the cells decreased slightly, but no short-circuit was observed between the cells and the substrate.

Stainless steel bowls of $0.5 \mathrm{~mm}$ in diameter were hit on the solar panel with a power supply. The power supply had a voltage of $100 \mathrm{~V}$ and a current of $3 \mathrm{~A}$. The particles passed through the panel as the same result of the $0.5 \mathrm{~mm}$ alumina particles. Discharging of about $100 \mathrm{~ms}$ occurred during this test. Figure 11 illustrates the signals of voltage and current of the impacted solar cell at the impact test. The voltage decreased about $40 \mathrm{~V}$ during the discharge. On the other hand, the current worked $3 \mathrm{~A}$ in constant. The discharge occurred damage on the panel is larger than the non discharge damages. The degradation of the electrical performance was lower than that in Fig. 10.

Some discharges occurred between the solar cells and the substrate at some tests, but no sustained arc discharge was detected.

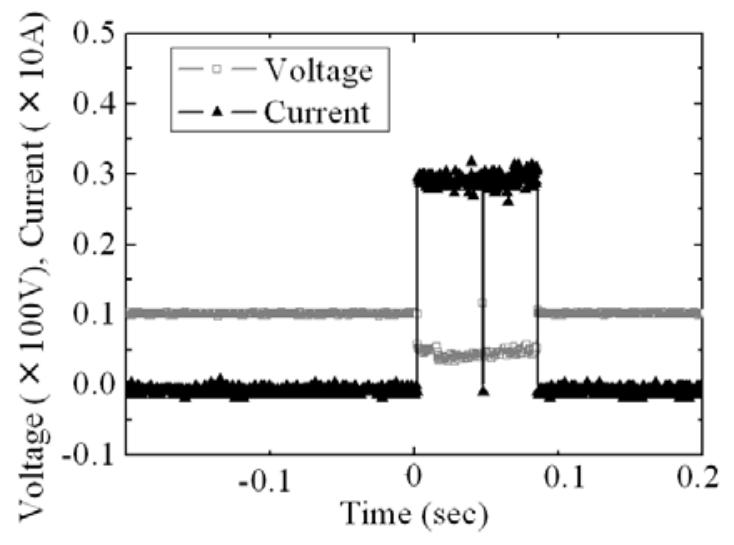

Fig.11. Change in voltage and current of the power supply provided the solar panel for the discharge.

\section{Summary}

Electrical performance degradation was evaluated as an effect of the impact of particles smaller than $0.5 \mathrm{~mm}$ in diameter at hypervelocity on solar panels provided with a power supply. Results show a slightly decreased performance, but no short-circuit occurred between the solar cells and the substrate. This degradation is insufficient to influence satellite systems.

\section{References}

1) Kawakita, S., et al.,: Sustained Arc Between Primary Power Cables of a Satellite, AIAA Paper 2004-5658, 2004.

2) Letin, V. A., et al.,: Solar Cell Shunting Under High Velocity Impact of Solid Particles, $19^{\text {th }}$ European Photovoltaic Solar Energy Conference, Paris (2004), pp.3644-3647.

3) Gerlach L.: HST-Solar Array 1 in Flight Power Generation Anomalies, HST Solar Array Workshop, 30-31 May 1995. 